\title{
Italian Deprivation Index and Dental Caries in 12-Year-Old Children: A Multilevel Bayesian Analysis
}

\author{
Domenica Matranga $^{a} \quad$ Guglielmo Campus $^{\mathrm{b}}$ Paolo Castiglia \\ Laura Strohmenger $^{d}$ Giuliana Solinas $^{c}$ \\ a Department of Sciences for Health Promotion and Mother and Child Care 'G. D'Alessandro', University of \\ Palermo, Palermo, bepartment of Surgery, Microsurgery and Medicine Sciences, School of Dentistry and \\ 'Department of Biomedical Sciences, Unit of Public Health, Laboratory of Epidemiology and Biostatistics, \\ University of Sassari, Sassari, and dWHO Collaborating Center for Epidemiology and Community Dentistry \\ of Milano, Milan, Italy
}

\section{Key Words}

12-year-old children · Bayesian models · Caries · Deprivation index $\cdot$ Multilevel analysis

\begin{abstract}
Evidence from the literature has shown that people with a lower socioeconomic status enjoy less good health than people with a higher socioeconomic status. The Italian deprivation index (DI) was used with the aim to evaluate the association between the DMFT index and risk factors for dental caries, including city population and DI. The study included 4,305 12-year-old children living in 38 cities classified by demographic size as small, midsize and large. Zero-inflated negative binomial multilevel regression models were used to assess risk factors for DMFT and to address excess of zero DMFT and overdispersion through a Bayesian approach. The difference in the average level of DMFT among children living in cities with different DI quintile was not statistically significant $(p=0.578)$. The DI and $\operatorname{In}($ population), included as city-level fixed effects in the two-level variance components model, were not statistically significant. Consuming sweet drinks on average increased the mean DMFT of a susceptible child, while having a highly educated mother reduced it. Un-
\end{abstract}

observed heterogeneity among cities was detected for the probability to be non-susceptible to caries (city-level variance $=0.26$ with $95 \%$ credibility interval $0.09-0.57$ ), while no territorial effect was found for the mean DMFT of the susceptible children. Our results suggest that the DI and city population did not play a role in explaining between-city variability. Interventions against social deprivation can be influential on the perception of oral health in Italian 12-year-old children to the extent that they can also affect individual level factors.

๑) 2014 S. Karger AG, Basel

Ill health and deprivation have been explored since the mid-19th century [Wagstaff et al., 1991; Mackenbach and Kunst, 1997] and nowadays are well documented [Marmot et al., 2010]. An important principle to reduce health inequalities is highlighted by the final report of the Commission on Social Determinants of Health set up by the World Health Organization [Marmot et al., 2008], the major goal of the WHO being to eliminate the extensive, preventable and unjust health inequalities which persist within and between countries.

\section{KARGER}

E-Mail karger@karger.com

www.karger.com/cre (c) 2014 S. Karger AG, Basel

0008-6568/14/0486-0584\$39.50/0
Prof. Giuliana Solinas

Department of Biomedical Sciences, Unit of Hygiene

Laboratory of Epidemiology and Biostatistics, University of Sassari

Via Padre Manzella, 4, IT-07100 Sassari (Italy)

E-Mail gsolinas@uniss.it 
Despite overall reductions in caries levels, there are still persistent inequalities among social classes. Evidence has shown that, within one country, people with a lower socioeconomic status (SES) enjoy less good health than people with a higher SES [Marmot et al., 1995; Reisine and Psoter, 2001]. Usually, SES is measured by indicators such as income or occupational status [Bertoldi et al., 2013]. Recently, new measures of SES have been proposed as alternatives to these conventional indicators [Blair et al., 2013]. Deprivation indexes (DIs) have given new impetus to measure health disparities in several groups defined by a variety of socioeconomic categorizations. Usually, DIs are used to synthesize, albeit indirectly, the ownership of resources, both material and social, at individual, family and geographical area levels [Morris and Carstairs, 1991]. The use of census data on small areas has the advantage of classifying individuals in terms of the level of material deprivation in their neighborhood. The small area approach can help to show the characteristics of a population which are relevant to health planning, such as demography, social circumstances, mortality and morbidity.

Enquiries examining the association between socioeconomic area characteristics and health events have, in the main, made use of the postcode sector (in Scotland) or ward (in England) as the area base [Jarman, 1983; Townsend et al., 1988; Carstairs and Morris, 1991]. Many studies have focused on using a measure of 'deprivation', i.e. a score composed of a number of social variables from the census. A deprivation score of this kind, producing a continuous variable (albeit artificial), has the benefit of offering opportunities for statistical analysis.

Also in Italy, a nationwide DI at municipality and census block level was developed using data drawn from the 2001 General Census of Population and Housing [Caranci and Costa, 2009]. To represent the multidimensionality of the social and material deprivation concept, variables measuring low level of education, unemployment, home non-ownership, one-parent family and house overcrowding have been considered. Over the past few decades, in most industrialized countries the prevalence of dental caries has varied [Petersen, 2003; Marthaler, 2004]. Studies on the etiology of dental caries have shown that small population groups maintain a high prevalence of this disease [Ueda et al., 2004; Masood et al., 2012], and others reported that the disparity of disease may be related to a more intense exposure to risk factors (gender, educational level of mothers, SES, oral hygiene habits, fluoride history, dental fluorosis, access to oral health services, sugar consumption, diet habits, area of residence) and to social deprivation [Patrick et al., 2006; Sabbah et al., 2009].

Italian Deprivation Index and Dental Caries
In Italy, the national epidemiological data show a low DMFT index in healthy subjects varying from a value of 6.9 in 13-year-old [Vogel et al., 1979] to 1.44 with a cariesfree percentage of $56.9 \%$ in 12 -year-old healthy subjects. From an explanatory point of view of disparities related to dental caries, it becomes interesting to explore the variability of dental caries distribution taking into account the hierarchy of interactions between the individual and environment at different levels [Locker and Ford, 1994].

The challenges of estimating the prevalence of dental caries and other features of the distribution of the DMFT index have received some attention from a statistical point of view. Methodological approaches have been proposed to understand caries risk factors and to counteract their development, consisting of modeling the DMFT index through zero-inflated models [Böhning et al., 1999; Solinas et al., 2009; Javali and Pandit, 2010; Lesaffre and Lawson, 2012; Matranga et al., 2013a], although recommendations are provided to enhance the use of these models [Preisser et al., 2012]. The topic of simultaneous occurrence of zero inflation and correlation has been thoroughly tackled by various studies for the analysis of hierarchical data for either study design or data collection procedures [Burnside et al., 2007; Moghimbeigi et al., 2008]. Furthermore, models for correlated zero-inflated data have been developed within a Bayesian framework as an alternative to the classical, frequentist approach [Dunson, 2001; Greenland, 2006]. These include zero-inflated models for correlated territorial data [Gschlößl and Gzado, 2008] and hurdle, zero-inflated and zero-altered models for longitudinal data [Neelon et al., 2010]. As shown elsewhere in detail, Bayesian estimation for zero-inflated dental caries modeling offers many computational advantages and the possibility of expressing statistical inference about parameters in terms of credibility intervals (CrIs) [Matranga et al., 2013b].

Considering these precepts, the aim of this study was to evaluate the association between the DMFT index and risk factors for dental caries, including two city-level factors, DI and city population. Data for this analysis were collected through the Italian Pathfinder survey [Campus et al., 2007] and were hierarchically structured as children within cities, within territorial macro-areas. The information at both individual and territorial levels was integrated through multilevel Bayesian zero-inflated models.

\section{Materials and Methods}

Data Source

Data from the Italian Pathfinder survey carried out from March 2004 to April 2005 were used as the source of the oral health out- 
Table 1. Distribution of DMFT and contextual factors by cities and by demographic size

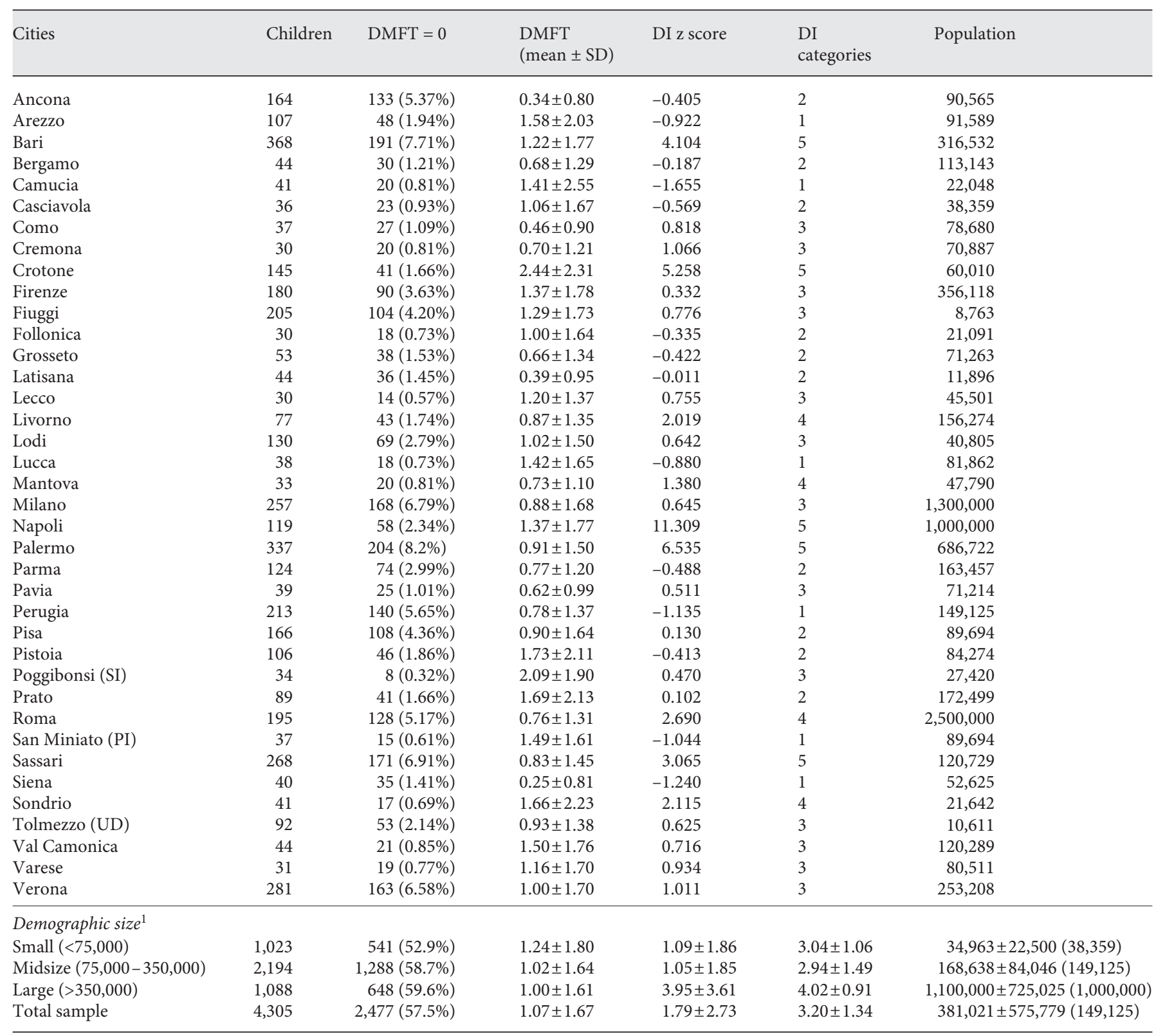

${ }^{1}$ With regards to demographic size analysis, mean \pm SD is given for DI z score and DI categories; mean \pm SD and median, in parentheses, are given for population.

comes and individual level covariates for the present paper. An original sample of 5,342 12-year-old children, randomly chosen in a multistage sampling frame extracted from twenty Italian regions, were enrolled and then examined. A detailed description of sampling techniques is reported in a separate paper [Campus et al., 2007]. Children were examined by calibrated operators according to the WHO guidelines [World Health Organization, 1997], and training and inter-examiner reliability were assessed before the start of the study [Castiglia et al., 2007].
The study design also included an ad hoc questionnaire with closed questions which focused on sociodemographic background, oral hygiene behavior and other information related to caries risk. Seven individual level variables were considered, with categories shown in parentheses and the first one as reference: gender (male, female), mother and father education (low, high), intake of fluoride (no, yes), sweet drinking, such as milk or sugar water, before sleeping (no, yes), intake of sweet foods (never/sometimes, often), and type of water (spring, tap, mineral). Low education was defined as people with no, pre-primary or primary education. 
Table 2. Relationship between five DI categories and DMFT, by demographic size

\begin{tabular}{|c|c|c|c|c|c|c|}
\hline DI categories & \multicolumn{2}{|l|}{ small } & \multicolumn{2}{|l|}{ midsize } & \multicolumn{2}{|l|}{ large } \\
\hline 1st quintile (least deprived) & $0.84 \pm 1.98$ & $-1.45 \pm 0.21$ & $1.12 \pm 1.66$ & $-1.04 \pm 0.11$ & - & - \\
\hline 2nd quintile (2nd least deprived) & $0.74 \pm 1.40$ & $-0.33 \pm 0.21$ & $0.96 \pm 1.63$ & $-0.21 \pm 0.26$ & - & - \\
\hline 5 th quintile (most deprived) & $2.44 \pm 2.31$ & $5.53 \pm 0^{\mathrm{a}}$ & $1.06 \pm 1.66$ & $3.67 \pm 0.51$ & $1.03 \pm 1.58$ & $7.78 \pm 2.10$ \\
\hline
\end{tabular}

a Only one city in this class.

To make sure to get accurate estimates, municipalities with less than 30 sampled children were excluded from the original sample. The current study included 4,305 12-year-old children, living in cities classified by demographic size as small $(<75,000$ inhabitants), midsize (between 75,000 and 350,000 inhabitants) and large (>350,000 inhabitants). Apart from population data, the Italian DI was considered at city level, calculated as the sum of standardized indicators of low education, unemployment, rented housing, oneparent family and high density in housing [Caranci and Costa, 2009]. This index was considered as a proxy of the socioeconomic level of each city. The relationship between DMFT and deprivation area was evaluated by the quintiles of DI ranked from the least deprived to the most deprived.

\section{Statistical Analysis}

To assess risk factors for DMFT data and to address excess of zero DMFT and overdispersion, a zero-inflated negative binomial (ZINB) regression model was considered, as it appeared to be the best-fitting model for this dataset [Campus et al., 2007]. The ZINB model constitutes a mixture of the NB distribution (NB component), from which all of the non-zero and a few of the zero values are observed to represent the 'susceptible' subpopulation of children, and the zero distribution (inflation component), from which only zero values are observed (structural zeros) to represent the subpopulation of 'non-susceptible' children who are considered to be not at risk [Preisser et al., 2012]. Sampled children (first level) were nested into 38 cities (second level) which, in turn, were grouped into North-East, North-West, Center, South and Islands macro-areas (third level).

A ZINB three-level model was initially considered, with random intercepts and slopes for DI and (ln-transformed) city population at second level and variance components at third level. The simplest and parsimonious ZINB variance components model was definitively fitted. The data augmentation procedure for Bayesian estimation was applied [Ghosh et al., 1999, 2006]. The deviance, defined as -2 times the log likelihood, was used to assess goodness of fit. The lower the deviance, the better the fit. Results were expressed as medians and 95\% CrIs of the posterior distribution of the model parameters. The full specification of the statistical model and the WinBUGS code [Spiegelhalter et al., 2003] used to fit the models are given as online supplementary material (www. karger.com/doi/10.1159/000358810).

Italian Deprivation Index and Dental Caries
As preliminary analysis, after computing the summary statistics at city level, the ANOVA test was used to test the null hypothesis of equality of DMFT index and equality of DI by demographic size, and to test the null hypothesis of equality of DMFT index by quintiles of DI. In order to overcome the positive within-city correlation, one-way ANOVA was applied to the city-specific proportions to compare the occurrence of zero DMFT and the distribution of individual factors by demographic size. When ANOVA test showed statistical significance, the Scheffé test for multiple comparison was used to assess statistical significance of post-hoc paired comparisons. The $\chi^{2}$ test was used to assess statistical significance of the distribution of individual factors at city level.

\section{Results}

Of the 4,305 individuals of the sample, 1,023 (23.8\%) were living in small cities, 2,194 (50.9\%) in midsize cities and $1,088(25.3 \%)$ in large cities. The total mean of DMFT was $1.07 \pm 1.67$ and, in detail, $1.24 \pm 1.80$ in small cities, $1.02 \pm 1.64$ in midsize cities and $1.00 \pm 1.61$ in large cities. However, the difference in the average level of DMFT among children living in cities with different demographic size was not significantly different $(p=0.210)$. The percentage of children with zero DMFT was $57.5 \%$ in the whole sample. It was maximum in larger towns (59.6\%) and decreased with decreasing demographic size (58.7\% and $52.9 \%$ in midsize and small towns, respectively), but the decreasing trend was not statistically significant $(\mathrm{p}=$ $0.979)$. On average, the DI was higher in the largest cities $(3.95 \pm 3.61)$ than in midsize $(1.05 \pm 1.85)(\mathrm{p}=0.004)$ and in small ones $(1.09 \pm 1.86)(\mathrm{p}=0.006)$ (table 1$)$.

The relationship between five DI quintiles and DMFT, by demographic size of cities, is shown in table 2 . The difference in the average level of DMFT among children living in cities with different DI quintiles was not statistically significant $(\mathrm{p}=0.578)$. 
Table 3. Distribution of individual factors at city level, $\mathrm{n}(\%)$

\begin{tabular}{|c|c|c|c|c|c|c|c|}
\hline Cities & $\begin{array}{l}\text { Gender = } \\
\text { female }\end{array}$ & $\begin{array}{l}\text { Mother } \\
\text { education = } \\
\text { high }\end{array}$ & $\begin{array}{l}\text { Father } \\
\text { education = } \\
\text { high }\end{array}$ & $\begin{array}{l}\text { Fluoride } \\
\text { intake = } \\
\text { yes }\end{array}$ & $\begin{array}{l}\text { Sweet beverage } \\
\text { before sleeping = } \\
\text { yes }\end{array}$ & $\begin{array}{l}\text { Sweet foods } \\
\text { intake = } \\
\text { often }\end{array}$ & $\begin{array}{l}\text { Type of } \\
\text { water }= \\
\text { mineral or tap }\end{array}$ \\
\hline Arezzo & $53(49.5)$ & $53(49.5)$ & 48 (44.9) & $79(73.8)$ & $8(7.5)$ & $59(55.1)$ & $99(92.5)$ \\
\hline Bari & $190(51.6)$ & $221(60.1)$ & $230(62.5)$ & $167(45.4)$ & $42(11.4)$ & $210(57.1)$ & $343(93.2)$ \\
\hline Casciavola & $18(50.0)$ & $22(61.1)$ & $19(52.8)$ & $18(50.0)$ & $4(11.1)$ & $22(61.1)$ & $34(94.4)$ \\
\hline Como & $12(32.4)$ & $22(59.5)$ & $22(59.5)$ & $32(86.5)$ & $3(8.1)$ & $25(67.6)$ & $36(97.3)$ \\
\hline Cremona & $15(50.0)$ & $17(56.7)$ & $16(53.3)$ & $24(80.0)$ & $5(16.7)$ & $22(73.3)$ & $29(96.7)$ \\
\hline Crotone & $77(53.1)$ & $66(45.5)$ & $70(48.3)$ & $33(22.8)$ & $26(17.9)$ & $93(64.1)$ & $126(86.9)$ \\
\hline Firenze & $94(52.2)$ & $108(60.0)$ & $95(52.8)$ & $112(62.2)$ & $14(7.8)$ & $114(63.3)$ & $171(95.0)$ \\
\hline Fiuggi & $109(53.2)$ & $110(53.7)$ & $112(54.6)$ & $116(56.6)$ & $29(14.2)$ & $127(62.0)$ & $160(78.1)$ \\
\hline Livorno & $41(53.3)$ & $39(50.7)$ & $38(49.4)$ & $43(55.8)$ & $5(6.5)$ & $51(66.2)$ & $76(98.7)$ \\
\hline Lodi & $64(49.2)$ & $71(54.6)$ & $69(53.1)$ & $85(65.4)$ & $10(7.7)$ & $102(78.5)$ & $126(96.9)$ \\
\hline Lucca & $22(57.9)$ & $26(68.4)$ & $24(63.2)$ & $20(52.6)$ & $1(2.6)$ & $24(63.2)$ & $21(55.3)$ \\
\hline Mantova & $16(48.5)$ & $21(63.6)$ & $17(51.5)$ & $24(72.7)$ & $1(3.0)$ & $20(60.6)$ & $32(97.0)$ \\
\hline Milano & $134(52.1)$ & $176(68.5)$ & $174(67.7)$ & $181(70.4)$ & $29(11.3)$ & $174(67.7)$ & 244 (94.9) \\
\hline Napoli & $53(44.5)$ & $61(51.3)$ & $62(52.1)$ & $31(26.1)$ & $17(14.3)$ & $67(56.3)$ & $105(88.2)$ \\
\hline Palermo & $141(42.0)$ & $226(67.3)$ & $232(69.1)$ & $162(48.2)$ & $18(5.4)$ & 175 (51.9) & $305(90.8)$ \\
\hline Parma & $66(53.2)$ & $108(87.1)$ & $97(78.2)$ & $69(55.7)$ & $12(9.7)$ & $76(61.3)$ & $121(97.6)$ \\
\hline Pavia & $21(53.9)$ & $19(48.7)$ & $17(43.6)$ & $26(66.7)$ & $1(2.6)$ & $30(76.9)$ & 37 (94.9) \\
\hline Perugia & $113(53.1)$ & $144(67.6)$ & $136(63.9)$ & $91(42.7)$ & $23(10.8)$ & $128(60.1)$ & $205(96.2)$ \\
\hline Pisa & $89(53.6)$ & $137(82.5)$ & $134(80.7)$ & $87(52.4)$ & $13(7.8)$ & $111(66.9)$ & $157(94.6)$ \\
\hline Pistoia & $61(57.6)$ & $60(56.6)$ & $48(45.3)$ & $62(58.5)$ & $5(4.7)$ & $63(59.4)$ & $95(89.6)$ \\
\hline Tolmezzo (UD) & $54(58.7)$ & $46(50.0)$ & $50(54.4)$ & $81(88.0)$ & $9(9.8)$ & $63(68.5)$ & $78(84.8)$ \\
\hline Val Camonica & $25(56.8)$ & $9(20.5)$ & $14(31.8)$ & $35(79.6)$ & $7(15.9)$ & $32(72.7)$ & $41(93.2)$ \\
\hline Varese & $14(45.2)$ & $20(64.5)$ & $17(54.8)$ & $25(80.7)$ & $3(9.7)$ & $27(87.1)$ & $29(93.6)$ \\
\hline Verona & $141(50.2)$ & $196(69.8)$ & $197(70.1)$ & $219(77.9)$ & $24(8.5)$ & $183(65.1)$ & $271(96.4)$ \\
\hline $\mathrm{p}$ value & 0.019 & $<0.001$ & $<0.001$ & $<0.001$ & 0.002 & $<0.001$ & $<0.001$ \\
\hline
\end{tabular}

The distribution of individual factors was statistically significant at city level (table 3), but not by demographic size (table 4 ). The DI was significantly lower on average for high $(1.70 \pm 2.68)$ than for low mother's education level $(1.95 \pm 2.80)(p=0.003)$. Differently, the DI was not significantly different on average between high (1.80 \pm $2.71)$ and low father's education level $(1.80 \pm 2.75)(\mathrm{p}=$ 0.879) (data not in tables).
The ZINB three-level model was initially considered, but unobserved heterogeneity at macro-area level was negligible for both the probability to be an excess zero (macro-area level variance $=0.04$ with 95\% CrI 0.00-0.27) and the mean DMFT level (macro-area level variance = 0.04 with 95\% CrI 0.00-0.25). The ZINB two-level model with random slopes for DI and $\ln$ (population) at city level was applied, but random slopes were not significantly 
Table 4. Distribution of individual factors by demographic size, $\mathrm{n}(\%)$

\begin{tabular}{llllll}
\hline Individual factors & \multicolumn{2}{l}{ Demographic size } & \multirow{2}{*}{ Total } & p value \\
\cline { 2 - 4 } & small & midsize & large & & \\
\hline Females & $510(49.9)$ & $1,145(52.2)$ & $525(48.3)$ & $2,180(50.6)$ & 0.303 \\
High mother education & $544(53.2)$ & $1,417(64.6)$ & $692(63.6)$ & $2,653(61.6)$ & 0.251 \\
High father education & $531(51.9)$ & $1,637(62.3)$ & $680(62.5)$ & $2,578(59.9)$ & 0.223 \\
Intake of fluoride (yes) & $623(60.9)$ & $1,341(61.1)$ & $572(52.6)$ & $2,536(58.9)$ & 0.161 \\
Sweet beverage before sleeping (yes) & $117(11.4)$ & $184(8.4)$ & $98(9.0)$ & $399(9.3)$ & 0.138 \\
Sweet foods intake (often) & $677(66.2)$ & $1,364(62.2)$ & $632(58.1)$ & $2,673(62.1)$ & 0.212 \\
Type of water (mineral or tap) & $902(88.2)$ & $2,028(92.4)$ & $997(91.7)$ & $3,927(91.2)$ & 0.904 \\
\hline
\end{tabular}

Table 5. ZINB two-level variance components model: medians and 95\% CrIs of posterior distribution of coefficients in a sample of 4,305 Italian 12-year-old children

\begin{tabular}{lcc}
\hline & Inflation component & NB component \\
\hline Fixed effects & & \\
Child level & $-0.30(-0.50 ;-0.09)$ & $0.12(0.02 ; 0.22)$ \\
$\quad$ Female vs. male & $0.21(-0.03 ; 0.45)$ & $-0.27(-0.39 ;-0.16)$ \\
$\quad$ Mother education (high vs. low) & $0.48(0.26 ; 0.73)$ & $-0.03(-0.13 ; 0.08)$ \\
$\quad$ Father education (high vs. low) & $-0.37(-0.74 ;-0.03)$ & $0.18(0.04 ; 0.33)$ \\
$\quad$ Sweet beverage (yes vs. no) & $0.08(-0.13 ; 0.29)$ & $-0.08(-0.18 ; 0.01)$ \\
$\quad$ Fluoride intake (yes vs. no) & $0.56(0.08 ; 1.09)$ & $-0.01(-0.22 ; 0.21)$ \\
$\quad$ Water intake (tap vs. spring) & $0.53(0.15 ; 1.01)$ & $-0.01(-0.16 ; 0.16)$ \\
$\quad$ Water intake (mineral vs. spring) & $-0.15(-0.36 ; 0.06)$ & $0.07(-0.03 ; 0.17)$ \\
$\quad$ Sweets intake (often vs. never/sometimes) & & $0.01(-0.03 ; 0.05)$ \\
City level & $-0.07(-0.16 ; 0.02)$ & $-0.01(-0.09 ; 0.06)$ \\
$\quad$ DI & $0.10(-0.09 ; 0.30)$ & \\
$\quad$ ln(population) & & \\
\hline Random effects & $0.26(0.09 ; 0.57)$ & \\
Intercept variance & $2.63(1.95 ; 3.56)$ & \\
\hline Overdispersion rate & $8,837(8,473 ; 9,243)$ & \\
Deviance & $57.4(55.9 ; 58.8)$ & \\
Estimated \% of zeros & & \\
\hline
\end{tabular}

different from each other (fig. 1). The ZINB two-level variance components model was definitively considered and DI and $\ln$ (population), included as city-level fixed effects, were not statistically significant (table 5). Females and children consuming sweet drinks, respectively, had $\exp (-0.30)=0.74(95 \%$ CrI 0.61-0.91) and $\exp (-0.37)=$ 0.70 (95\% CrI 0.48-0.97) times lower odds of being an extra zero, compared to males and children not consuming. By contrast, children drinking tap water or mineral water had higher odds to be an extra zero compared to children drinking spring water. Furthermore, children with higheducated father had $\exp (0.48)=1.62(95 \%$ CrI $1.30-2.08)$ times higher odds of being an extra zero than children with a lower-educated father. With regards to the NB part of the ZINB model, on average, females had $\exp (0.12)=$ 1.13 (95\% CrI 1.02-1.25) times higher DMFT than males in the susceptible population. Analogously, consuming sweet drinks on average increased the mean DMFT of a susceptible child, while having a highly educated mother reduced it. Unobserved heterogeneity was significant for the probability of being a structural zero DMFT (city-level variance $=0.26$ with $95 \%$ CrI $0.09-0.57$ ), but not for the mean DMFT level of the susceptible population. 

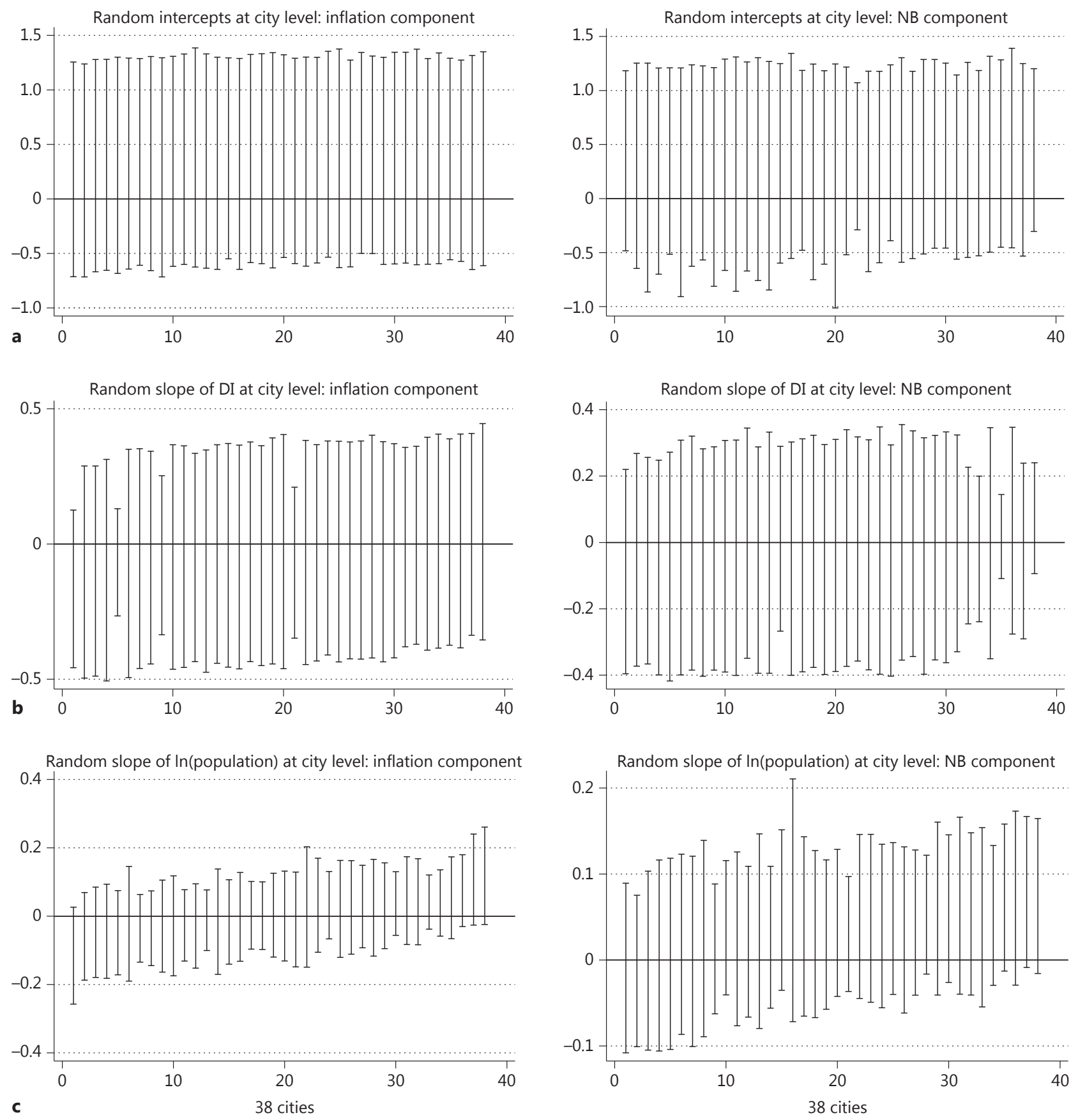

Fig. 1. ZINB random slopes model: random intercepts (a), random slopes of DI (b) and $\ln$ (population) (c) for the inflation (left) and the NB (right) components. 


\section{Discussion}

The aim of this study was to investigate the association between dental caries, as measured by the DMFT index, and dental risk factors, including a DI and (ln-transformed) city population. For this purpose a ZINB regression model was applied to data on 4,305 12-year-old children extracted from the Italian Pathfinder study and multilevel Bayesian modeling was used for parameter estimation. In Bayesian analysis, all forms of uncertainty are expressed in terms of probability. The approach starts with the formulation of a model with which we hope to describe the situation of interest. We then assume a prior distribution over the unknown parameters of the model, which is meant to capture our beliefs about the situation before observing the data. After observing some data, we apply Bayes' rule to obtain a posterior distribution for these unknowns, which takes account of both the prior and the data. Prior elicitation plays an important role in Bayesian inference. As Kadane and Wolfson [1998] pointed out, the experimenters' knowledge or experience can be essential information, which makes the Bayesian inference more plausible. When no prior information is available, a non-informative or vague prior is chosen that will not influence the posterior distribution. If prior information is available, it should be appropriately summarized by the prior distribution.

In dental caries epidemiology, the use of prior information about the DMFT parameter in Bayesian modeling can be very attractive, especially in observational studies, where neither random sampling nor randomization is performed and uncontrolled sources of bias, such as confounding, selection bias and measurement error, can be present [Dunson, 2001; Greenland, 2006]. Alternatively, as the data considered in this paper were randomly chosen in a multistage random sampling frame, the advantages of the Bayesian framework have to be ascribed to the computational flexibility and the ease of estimation of zero-inflated modeling. In classical methods such as maximum likelihood, parameter estimates are found through numerical optimization, which can be computationally intensive in the presence of many unknown parameter values. Alternatively, Bayesian parameter estimates are found by drawing realizations from the posterior distribution [Greenland, 2006].

To the best of our knowledge, this paper is the first to have considered the role of deprivation and municipality in dental caries epidemiology in Italy.

There is consistent evidence throughout Europe that people at a socioeconomic disadvantage suffer a heavier burden of oral health problems than their better-off coun-

Italian Deprivation Index and Dental Caries terparts [Petersen, 2003]. The reasons of disparities in oral health are complex.

Various studies confirmed that socioeconomic indexes are sensitive to variations in oral health and oral health behaviors and can be used to identify small areas with high levels of need for dental treatment and oral health promotion services [Locker, 1993; Pine et al., 2004].

In the EU Resolution on Reducing Health Inequalities (dated March 8, 2011), the European Parliament acknowledged that 'the EU faces a challenge arising from the wide disparities in physical and mental health which exist and are growing between and within EU Member States, noting that inequalities in health between people in higher and lower educational, occupational and income groups have been found in all Member States'. The European Parliament specifically recognized that substantial inequalities can be seen in the prevalence of most specific forms of disability and of most specific chronic non-communicable diseases, including oral diseases, and that health inequalities are linked to problems in accessing healthcare both for economic reasons for everyday treatment such as dental care and prevention and as a result of poor distribution of medical resources in certain areas of the European Union (http://www.oralhealthplatform.eu/eu-oral-health-policy).

In this paper, unobserved heterogeneity among cities was detected only for the probability to be non-susceptible to caries, while no territorial effect was found for the mean DMFT of the susceptible children. As the previous analysis of this dataset [Campus et al., 2007] had already shown, even if the level of dental caries recorded in Italian 12 -year-olds is quite low and very close to the value fixed by the WHO, there are significant differences in the percentage of non-susceptible children among geographical sections, with the lowest percentage in the Southern Italy compared to the two Northern macro-areas.

The relationship between DMFT and DI was not statistically significant, despite the trend observed in small cities where mean DMFT increases with quintiles of DI. One possible reason can be related to the strong inverse relationship between dental caries and contact with primary dental care services [Tickle et al., 2000]. The inadequate supply of oral public healthcare services in small Italian centers makes the access to care more difficult for deprived people.

The first hypothesis to explain why the DI and the (lntransformed) city population did not result in playing a different role variable from town to town concerns the DI used in this study. It cannot be excluded that the analysis of DI at the city level may miss an existing association of 
DI and DMFT at the census block level. However, considering this variable at this detail was not possible because of much missing or inaccurate information regarding the address of sampled children in the considered dataset. Furthermore, differently from other measures as the Townsend and the Jarman indexes, more often used in other literature on the sametopic [Jarman, 1983; Townsend et al., 1988; Morgan and Treasure, 2001], the Italian DI included some aspects of social deprivation concerning education, unemployment, disadvantaged housing and familiar conditions, but excluded other important aspects related to vulnerable groups, including disadvantaged migrant groups and people belonging to ethnic minorities, children and adolescents, people with disabilities, with a special focus on mental illness, patients diagnosed with chronic diseases or conditions, older people, people living in poverty, and people affected by alcoholism and drug addiction. The limitations of statistical indexes to measure deprivation, especially in areas with pronounced regional income disparities, are well known [Kunst et al., 2005; Franzini and Giannoni, 2010]. To represent the multidimensionality of the social deprivation, a DI specific to the aims of dental epidemiology should be developed at smallarea level, including statistics about dental services as, for example, dentists to population ratio.

The second hypothesis concerns characteristics of accessing oral healthcare in Italy, with poor distribution of public dental clinics and low propensity to dental visit attendance with slight variability throughout Italy [ISTAT, 2005]. In Italy, oral health education programs in schools are at an early stage and distributed as leopard spots, without significant differences along territory. Non-fluoridated tap water and fluoride-containing toothpastes are widespread throughout the nation [Pizzo et al., 2007], and this circumstance can explain why caries susceptibility in
Italy does not vary from small to large and midsize cities, as it was demonstrated in some developing countries [Tagliaferro et al., 2004]. Some papers in the literature [Gratrix and Holloway, 1994; Ellwood and O'Mullane, 1995; McGrady et al., 2012] pointed out the association between social deprivation and dental caries through the combined effect of water fluoridation as means of caries prevention, while the Italian legislation establishes a maximum limit for the presence of fluoride in drinking water (http:// www.camera.it/parlam/leggi/deleghe/01031dl.htm).

Another result of this study was the preeminent role of factors at individual level. Maternal education plays an important function in the oral health of children. To support early oral health education, there is new evidence that mothers of all socioeconomic levels are equally interested and engaged in their children's overall health [Lee, 2010]. However, mothers of higher social strata and income levels have minor barriers of access to educational information in a culturally sensitized matter.

Our results suggest that actions against social deprivation can be influential on the perception of oral health in Italian 12-year-old children to the extent that they can also affect individual-level factors, as oral health programs involving the mother's participation, and can be effective in improving dental health behavior and perceived self-efficacy in children.

\section{Authors' Contributions}

D.M. and G.S. conceived and designed the study; G.C., P.C. and L.S. performed the clinical examination; D.M. and G.S. analyzed and interpreted the data; D.M., G.C., P.C., L.S. and G.S. wrote the paper; D.M. and G.S. critically revised the manuscript. All authors read and approved the final manuscript.

\section{References}

Bertoldi C, Lalla M, Pradelli JM, Cortellini P, Lucchi A, Zaffe D: Risk factors and socioeconomic condition effects on periodontal and dental health: a pilot study among adults over fifty years of age. Eur J Dent 2013;7:336-346.

- Blair YI, McMahon AD, Macpherson LMD: Comparison and relative utility of inequality measurements: as applied to Scotland's child dental health. PLoS One 2013;8:e58593.

Böhning D, Dietz E, Schlattmann P, Mendonça L, Kirchner U: The zero-inflated Poisson model and the decayed, missing and filled teeth index in dental epidemiology. J R Statist Soc A 1999;162:195-209.
Burnside G, Pine CM, Williamson PR: The application of multilevel modelling to dental caries data. Stat Med 2007;26:4139-4149.

Campus G, Solinas G, Cagetti MG, Senna A, Minelli L, Majori S, Montagna MT, Reali D, Castiglia P, Strohmenger L: National Pathfinder survey of 12-year-old children's oral health in Italy. Caries Res 2007;41:512-517.

Caranci N, Costa G: Un indice di deprivazione a livello aggregato da utilizzare su scala nazionale: giustificazioni e composizione dell'indice; in Costa G, Cislaghi C, Caranci N (eds): Le disuguaglianze di salute. Problemi di definizione e di misura. Salute e società. Rome, Franco Angeli, 2009.
Carstairs V, Morris R: Deprivation and health in Scotland. Aberdeen, Aberdeen University Press, 1991.

Castiglia P, Campus G, Solinas G, Maida C, Strohmenger L: Children's oral health in Italy: training and clinical calibration of the examiners for the National Pathfinder about caries disease. Oral Health Prev Dent 2007;5:255261.

Dunson DB: Commentary: Practical advantages of Bayesian analysis of epidemiologic data. Am J Epidemiol 2001;153:1222-1226. 
Ellwood RP, O'Mullane DM: The association between area deprivation and dental caries in groups with and without fluoride in their drinking water. Community Dent Health 1995; 12:18-22.

Franzini L, Giannoni M: Determinants of health disparities between Italian regions. BMC Public Health 2010;10:296.

Ghosh SK, Mukhopadhyay P, Lu JC: Bayesian analysis of zero inflated regression models. Invited talk delivered at Indian Statistical Institute. Calcutta, Applied Statistics Unit, 1999.

-Ghosh SK, Mukhopadhyay P, Lu JC: Bayesian analysis of zero-inflated regression models. J Stat Plan Inference 2006;136:1360-1375.

Gratrix D, Holloway PJ: Factors of deprivation associated with dental caries in young children. Community Dent Health 1994;11:66-70.

Greenland S: Bayesian perspectives for epidemiological research: I. Foundations and basic methods. Int J Epidemiol 2006;35:765-775.

- Gschlößl S, Gzado C: Modelling count data with overdispersion and spatial effects. Stat Pap 2008;49:531-552.

ISTAT: Indagine multiscopo sulle famiglie, condizioni di salute e ricorso ai servizi sanitari 2004-2005.

-Jarman B: Identification of underprivileged areas. Br Med J 1983;286:1705-1709.

-Javali SB, Pandit PV: Using zero inflated models to analyze dental caries with many zeroes. Indian J Dent Res 2010;21:480-485.

Kadane JB, Wolfson LJ: Experiences in elicitation. Statistician 1998;47:20.

-Kunst AE, Bos V, Lahelma E, Bartley M, Lissau I, Regidor E, Mielck A, Cardano M, Dalstra JA, Geurts JJ, Helmert U, Lennartsson C, Ramm J, Spadea T, Stronegger WJ, Mackenbach JP: Trend in socioeconomic inequalities in selfassessed health in 10 European countries. Int J Epidemiol 2005;34:295-305.

Lee JK: A study on mothers' oral health knowledge and oral health management behavior of children. J Korean Soc Dent Hyg 2010;10:93106.

Lesaffre E, Lawson A: Bayesian Biostatistics. Chichester, John Wiley \& Sons, 2012.

Locker D: Measuring social inequality in dental health services research: individual, household and area-based measures. Community Dent Health 1993;10:139-150.

Locker D, Ford J: Evaluation of an area-based measure as an indicator of inequalities in oral health. Community Dent Oral Epidemiol 1994;22:80-85.

Mackenbach JP, Kunst AE: Measuring the magnitude of socio-economic inequalities in health: an overview of available measures illustrated with two examples from Europe. Soc Sci Med 1997;44:757-771.

Marmot M, Atkinson T, Bell J, Black C, Broadfoot P, Cumberlege J, Diamond I, Gilmore I, Ham C, Meacher M, Mulgan G: Fair Society, Healthy Lives: The Marmot Review Strategic Review of Health Inequalities in England post-2010. London, University College London, 2010.
Marmot MG, Bobak M, Smith GD: Explanations for social inequalities in health; in Amick BC, Levine S, Tarlov AR, Walsh DC (eds): Society and Health. New York, Oxford University Press, 1995, pp 172-210.

Marmot M, Friel S, Bell R, Houweling TAJ, Taylor $S$; Commission on Social Determinants of Health: Closing the gap in a generation: health equity through action on the social determinants of health. Lancet 2008;372:1661-1669. Available at: http://www.who.int/social_determinants/thecommission/finalreport/en/ index.html (accessed August 3, 2013).

- Marthaler T: Changes in dental caries 1953-2003. Caries Res 2004;38:173-181.

Masood M, Yusof N, Hassan MI, Jaafar N: Assessment of dental caries predictors in 6-year-old school children - results from 5-year retrospective cohort study. BMC Public Health 2012;12:989.

Matranga D, Castiglia P, Solinas G: Challenges in dental statistics: data and modeling. Epidemiol Biost Pub Health 2013a;10:e87591-e87598.

-Matranga D, Firenze A, Vullo A: Can Bayesian models play a role in dental caries epidemiology? Evidence from an application to the BELCAP data set. Community Dent Oral Epidemiol 2013b;41:473-480.

-McGrady MG, Ellwood RP, Maguire A, Goodwin M, Boothman N, Pretty IA: The association between social deprivation and the prevalence and severity of dental caries and fluorosis in populations with and without water fluoridation. BMC Public Health 2012;12:1122.

Moghimbeigi A, Eshraghian MR, Mohammad K, McArdle B: Multilevel zero-inflated negative binomial regression modeling for overdispersed count data with extra zeros. J Appl Stat 2008;35:1193-1202.

Morgan MZ, Treasure ET: Comparison of four composite deprivation indices and two census variables in predicting dental caries in 12 -year-old children in Wales. Community Dent Health 2001;18:87-93.

Morris R, Carstairs V: Which deprivation? A comparison of selected deprivation indexes. J Public Health Med 1991;13:318-326.

-Neelon BH, O’Malley AJ, Normand STL: A Bayesian model for repeated measures zero-inflated count data with application to outpatient psychiatric service use. Stat Modelling 2010;10: 421-439.

Patrick DL, Lee RS, Nucci M, Grembowski D, Jolles CZ, Milgrom P: Reducing oral health disparities: a focus on social and cultural determinants. BMC Oral Health 2006;6(suppl 1):S4.

Petersen PE: The World Oral Health Report 2003: continuous improvement of oral health in the 21 st century - the approach of the WHO Global Oral Health Programme. Community Dent Oral Epidemiol 2003;31(suppl 1):3-24.
Pine CM, Adair PM, Petersen PE, Douglass C, Burnside G, Nicoll AD, Gillett A, Anderson R, Beighton D, Jin-You B, Broukal Z, Brown JP, Chestnutt IG, Declerck D, Devine D, Espelid I, Falcolini G, Ping FX, Freeman R, Gibbons D, Gugushe T, Harris R, Kirkham J, Lo EC, Marsh P, Maupomé G, Naidoo S, RamosGomez F, Sutton BK, Williams S: Developing explanatory models of health inequalities in childhood dental caries. Community Dent Health 2004;21(1 suppl):86-95.

-Pizzo G, Piscopo MR, Pizzo I, Giuliana G: Community water fluoridation and caries prevention: a critical review. Clin Oral Invest 2007; 11:189-193.

- Preisser JS, Stamm JW, Long DL, Kinkade ME: Review and recommendations for zero-inflated count regression modeling of dental caries indices in epidemiological studies. Caries Res 2012;46:413-423.

Reisine ST, Psoter W: Socioeconomic status and selected behavioral determinants as risk factors for dental caries. J Dent Educ 2001; 65(10):1009-1016.

- Sabbah W, Tsakos G, Chandola T, Sheiham A, Watt RG: The role of health related behaviours in the socioeconomic disparities in oral health. Soc Sci Med 2009;68:298-303.

Solinas G, Campus G, Maida C, Sotgiu G, Cagetti MG, Lesaffre E, Castiglia P: What statistical method should be used to evaluate risk factors associated with $\mathrm{dmfs}$ index? Evidence from the National Pathfinder Survey of 4-year-old Italian children. Community Dent Oral Epidemiol 2009;37:539-546.

Spiegelhalter DJ, Thomas A, Best NG, Lunn D (eds): WinBUGS Version 1.4 User Manual. Cambridge, MRC Biostatistics Unit, 2003. http://www.mrc-bsu.cam.ac.uk/bugs/.

Tagliaferro EP, Cypriano S, de Sousa Mda L, Wada RS: Caries experience among schoolchildren in relation to community fluoridation status and town size. Odontol Scand 2004;62:124-128.

Tickle M, Moulding G, Milsom K, Blinkhorn A: Dental caries, contact with dental services and deprivation in young children: their relationship at a small area level. Br Dent J 2000;189: 376-379.

Townsend P, Phillimore P, Beattie A: Health and Deprivation, Inequality and the North. New York, Croom Helm Ltd, 1988.

-Ueda EMO, Dezan CC, Frossard WTG, Salomão F, Morita MC: Prevalence of dental caries in 3- and 5-year-old children living in a small Brazilian city. J Appl Oral Sci 2004;12:34-38.

-Vogel G, Strohmenger L, Ferrari PA, Weinstein R, Carrassi A, Landenna P: Epidemiologic surveying of dental-periodontal disease in the compulsory school population of the city of Milan. Mondo Odontostomatol 1979;21:744.

Wagstaff A, Paci P, van Doorslaer E: On the measurement of inequalities in health. Soc Sci Med 1991;33:545-557.

World Health Organization: Oral Health Surveys: Basic Methods. Geneva, WHO, 1997. 